\title{
La escucha analítica como lugar de encuentro
}

RESUMEN: ¿En qué se diferencia un psicoanálisis de una psicoterapia psicoanalítica? Una discusión.

PALABRAS CLAVES: Psicoterapia psicoanalítica, psiquiatría dinámica.
SUMMARY: Which is the difference between a psychoanalysis and a psychoanalytic psychotherapy? A discussion.

KEY WORDS: Psychoanalytic psychoteraphy, dinamic psychiatry.

«Estimados colegas: Ustedes saben que nunca nos enorgullecimos de poseer un saber o un poder-hacer completos y concluidos; hoy, como siempre, estamos dispuestos a admitir las imperfecciones de nuestro conocimiento, a aprender cosas nuevas y a modificar nuestros procedimientos toda vez que se los pueda sustituir por algo mejor. Nos reencontramos hoy tras largos años de separación y de dura prueba; este reencuentro me mueve a pasar revista al estado actual de nuestra terapia, a la cual debemos sin duda la posición que tenemos en la sociedad de los hombres y a observar en perspectiva las nuevas direcciones en que podría desarrollarse» (1). Con estas palabras abre Freud su conferencia en el Congreso de Budapest en 1918 que tituló «Nuevos caminos de la terapia psicoanalítica».

La Gran Guerra ha dejado una enorme secuela tras de sí, con la aparición de gran cantidad de neurosis traumáticas. Es además el final del imperio Austrohúngaro y de la concepción de un modelo de sociedad. El Congreso de Psicoanálisis que se celebra en Budapest en 1918 marca este cambio que se está produciendo en la historia europea. Empiezan a plantearse nuevos caminos, si hay o no diferencias entre Psicoanálisis y Psicoterapia psicoanalítica, así como la necesidad de dar respuesta a una enorme demanda que el final de la guerra ha generado. En palabras del propio Freud: «Se nos planteará la tarea de adecuar nuestra técnica a las nuevas condiciones... nos veremos precisados a buscar para nuestras doctrinas teóricas la expresión más simple e intuitiva... Y también es muy probable que en la aplicación de nuestra terapia a las masas nos veamos precisados a alear el oro puro del análisis con el cobre de la sugestión directa y quizás el influjo hipnótico vuelva a hallar cabida, como ha ocurrido en el tratamiento de los neuróticos de guerra. Pero cualquiera que sea la forma de esta psicoterapia para el pueblo, y no importa qué elementos la constituyan finalmente, no cabe ninguna duda de que sus ingredientes más eficaces e importantes seguirán siendo los que ella tome del psicoanálisis riguroso, ajeno a todo partidismo».

Desde ese Congreso al día de hoy han pasado muchos años y con la perspectiva del tiempo puede uno cerciorarse de la enorme influencia que las ideas de Freud y su obra ha ejercido sobre la cultura contemporánea -desde el punto de vista científico, filosófico, literario, social y cultural-. A pesar de ello y tras un siglo, el XX, donde el psicoanálisis se ha consolidado como una terapéutica que ha impregnado 
la psiquiatría y la práctica psiquiátrica, los comentarios y la problemática que Freud plantea en esta conferencia siguen a nuestro juicio aún vigentes.

Cuando el psicoanálisis se ha extendido a la práctica pública y se ha hecho cargo de cierta demanda que antes quedaba fuera de sus fronteras, ¿puede afirmarse que ha perdido el «oro» puro del análisis, o sigue conservando sus elementos más importantes? Cuando un psicoanalista teoriza y escribe habría que preguntarse ¿sobre qué pacientes está hablando?

Jorge Ulnik, psiquiatra y psicoanalista argentino, autor de una magnífica revisión crítica de la obra teórica de Pierre Marty, (2) y que habitualmente trabaja con enfermos psicosomáticos se hace esta misma pregunta, al reflexionar sobre el tratamiento de esta patología y el tipo de pacientes que uno se encuentra en su tarea diaria.

Se pregunta Ulnik: ¿son los mismos pacientes los que él ve en un hospital público de Buenos Aires, que los pacientes que ve Pierre Marty, junto con otros médicos que permanecían en la entrevista, según el viejo modelo médico de maestro y alumnos, o los pacientes que en sus lujosos despachos de París ven McDougall y Smirgell?

Al interrogarse de este modo, él está planteando cómo el lugar puede cambiar la demanda del paciente e incluso la escucha. Alguien colocado en otra posición, escucha de otra forma y teoriza de otra forma.

¿Es el mismo el lugar desde donde uno escucha a un paciente psicótico, a un paciente neurótico o a un paciente perverso? ¿No nos obliga el paciente con su patología y su estructura psíquica, en ocasiones, a cambiar el lugar y por tanto la escucha?

¿Es igual el trabajo que un psicoanalista puede realizar en la práctica privada, protegido por un encuadre cuyas condiciones favorecen la deseada «neurosis de transferencia», frente al del profesional de una consulta pública, con un tiempo muy limitado y un espacio casi siempre inadecuado? ¿Son los mismos los pacientes que son capaces de establecer un compromiso de trabajo que incluya el pago de unos honorarios que aquellos que esperan, a veces con extrema paciencia, a que el psiquiatra acabe con las urgencias, los retrasos o las pausas para el café? ¿Qué pasa con la intimidad y la confidencialidad en un despacho cuya puerta se abre varias veces durante la sesión por los motivos más nimios?

Numerosos autores han aportado modificaciones con respecto a la técnica clásica en el abordaje de pacientes graves, que incluyen el uso restringido de la interpretación o el diván. De hecho las indicaciones de un tratamiento psicoanalítico se han ampliado desde los primeros tiempos de Freud gracias a estas aportaciones, aunque a veces las múltiples escuelas y puntos de vista nos hagan pensar que nosotros vemos otros pacientes o que los vemos de forma diferente. 
C. es una mujer de 35 años que acude a una consulta privada para revisión de su medicación. Se ha cambiado su nombre hace 10-11 años porque el verdadero quiere decir soledad y ella odia la soledad, al haber sido obligada a sufrirla. Ha recibido múltiples tratamientos para sus síntomas depresivos, con mejorías transitorias. Lo que llama la atención es su descuido general: en los tratamientos, en su aspecto, en su alimentación y en toda su vida, de la cama al sillón, con grandes dolores de cabeza que le impiden salir de casa o ver a sus amistades. El empeoramiento actual lo atribuía a una visita a su madre a Galicia «porque mi madre está muy loca, pero no va al psiquiatra». «Siempre ha dicho que yo sería una desgraciada cabeza loca».

C. sólo acude a cuatro visitas. Después de la primera entrevista sus jaquecas son tan fuertes que tarda semanas en volver a la consulta, dejando mensajes que informan de que no ha venido, como si el terapeuta no fuera a notarlo. En la segunda visita ya avisa que no va a poder seguir viniendo, pero vuelve con una grabadora como regalo, para que el terapeuta pueda escuchar sus sueños. La última vez que acude tiene «bulimia», come a cucharadas nata, mantequilla y chocolate, mezclados, hasta que no puede levantarse y falta en su trabajo.

Éste es un sueño entre la segunda y la tercera visita: «siempre sueño con una casa super-bonita, me supongo en el sueño que es de mi madre pero no la habita nadie. Es todo precioso pero está sin estrenar. Yo no le digo a mi madre que visito la casa y ella no me dice que la tiene. Da gusto estar en ella... Después con mi madre persiguiéndome, una amiga que iba conmigo apareció con un brazo roto porque mi madre la había cogido. Como no conseguía cogerme entró en razón, se tranquilizó y cambió de táctica para acercarse a mí. Me dijo - te voy a enseñar mi casa- muy amable, y yo accedí. La casa era horrible, unas escaleras anchas en tres bloques. Era más grande el espacio de escaleras que la casa. En el primero las puertas eran verjas de cristal opaco y con hierros. Entrabas y a mano izquierda estaba la cocina que no era una cocina, era una silla con un fogón de dos fuegos, un escurridor, un váter tapado por una cortina y una cama plegada también tapada por cortinas.

A mano derecha había una mesa de esas que se cierran; si te sentabas a comer lo hacías contra la pared. Subías otras escaleras y había un salón enorme sin amueblar, no sabías lo que era, sólo tenía unos bancos viejos y una chimenea con ceniza. Le dije a mi madre que para qué quería los bancos - para nada, llévatelos- hice un paquete con ellos. No tenía nada que ver con la casa que yo sueño que creo que es la casa de mi madre. Es la primera vez que mi madre me enseña la casa en sueños. Siempre me persigue y siempre fuera de la casa. Es muy difícil llegar a mi madre».

Pacientes como C. no eran analizables en los primeros tiempos del psicoanálisis porque no podían establecer una neurosis de transferencia. Nadie podría hablar de neurosis, pero ¿se puede negar la existencia de un movimiento transferencial? 
Las preguntas anteriores nos llevan a una reflexión sobre la escucha analítica ¿Qué hay de común en la escucha de las diferentes estructuras que pueda ser considerado como el punto denominador de toda escucha que se pretenda analítica? ¿Depende la escucha del encuadre? En definitiva, y atendiendo a la escucha que se realiza ¿en qué se diferencia un psicoanálisis de una psicoterapia psicoanalítica?

En este trabajo trataremos dar cuenta de estas cuestiones y para ello nos sumergiremos en la obra freudiana en un intento de poder definir lo que para nosotros es el trabajo analítico; aquello que en la escucha de los pacientes, sea cual sea su patología, debe de estar presente para que la palabra del paciente avenga en palabra analítica.

Un recorrido que iniciamos en lo que se ha dado en llamar la era prepsicoanalítica o los comienzos, donde lo que hubo fue una superconcienciación del paciente; se trataba de llevar a conciencia aquello que se suponía que por la represión había quedado fuera de ella. Recordar y abreaccionar eran las metas que se perseguían con ayuda del método hipnótico.

En un segundo período y tras renunciar a la hipnosis, pasó a primer plano la tarea de colegir desde las ocurrencias libres del analizado aquello que él denegaba recordar. De entre las asociaciones del paciente, el analista trata de ir recogiendo y construyendo con eso algo que pueda parecerse al recuerdo. Se pretendía sortear las resistencias mediante el trabajo interpretativo, y la comunicación de sus resultados al paciente. Ahora la abreacción es relegada y parece ser sustituida por el gasto de trabajo que el analizado tiene que prestar al vencer como le es prescrito por la obediencia a la regla psicoanalítica fundamental la crítica a sus ocurrencias. Es decir la abreacción es sustituida por el trabajo con las resistencias.

En un tercer período se plasmó la consecuente técnica que hoy día empleamos; el médico renuncia a enfocar un momento o un problema determinado (se conforma con estudiar la superficie psíquica que el analizado presenta cada vez, es decir en cada sesión) y se vale del arte interpretativo en lo esencial para discernir las resistencias que se recortan en el enfermo y hacérselas conscientes. Poco a poco el analista va renunciando a su deseo de hallar algo y se va colocando en una perspectiva de encuentro (es decir estar en una actitud de espera para leer en la superficie, en el texto manifiesto).

Apuntamos ya aquí un dato importante: La perspectiva de encuentro.

La palabra perspectiva nos da la idea de un cambio de posicionamiento, una nueva manera de mirar. Se esta ahí en espera pero con una nueva mirada dirigida hacia algo que todavía no se conoce, algo que emana del encuentro con otra subjetividad, la del paciente. 
Una actitud que por su renuncia al deseo de hallar algo no quiera decir pasiva. Se trata de algún modo de una «actividad» enfocada hacia otro escenario. En palabras de Racker (3) diríamos que la «atención flotante» no es más que un solo aspecto (aunque fundamental) del complejo proceso de la comprensión del inconsciente. Se entiende por qué Freud subrayó este aspecto: era lo nuevo y distinto; pero no podemos olvidar que aunque se haga énfasis en el carácter pasivo, escuchar bien y escuchar con empatía tienen también su aspecto activo.

Tendemos a identificarnos, e identificarse es un proceso mental, en parte activo, implicando, además la reproducción de la actividad psicológica del objeto. Dejamos que el material penetre en nosotros y a veces vibra inmediatamente la cuerda que fue «tocada»; pero otras veces esta recepción debe ser seguida por un proceso activo en el que nosotros como analistas «tocamos» y detectamos lo penetrado con nuestro sentir y pensar inconsciente, para poder, finalmente, unirnos con él.

Un pequeño texto de Freud de 1912 Consejos al médico en el tratamiento psicoanalítico (4) nos sirve para reflexionar sobre dos aspectos que tienen importancia en la escucha del paciente y en el encuentro afectivo con él: la atención flotante a la asociación libre y la contratransferencia. Pensamos que son indisociables y que están en permanente comunicación, y que su importancia y lugar en la escucha ha cambiado desde la fecha de este texto freudiano hasta hoy día.

Freud en esos Consejos al médico en el tratamiento psicoanalítico habla de algunas reglas técnicas. Se plantea algo tan elemental como: ¿se puede retener en la memoria los innumerables nombres, fechas y detalles de cada paciente sin confundir este material con el de otros pacientes? Parece que el valor de la escucha debe ir más allá de la recopilación (o recogida intencional) de datos. Freud da a entender que los esfuerzos de retener voluntariamente la información consumen energía y sesgan nuestra atención, mientras que la atención flotante ahorra esfuerzos inadecuados y encamina hacia una buena escucha.

Así, para darse una escucha verdadera, singular y única, parece que hemos de reivindicar la libre circulación de la palabra del paciente. Podemos pensar que una escucha psicoanalítica hace innecesario y puede que inoportuno anotar todo aquello que dice el paciente; si el analista recibe con verdadero interés el relato del paciente no ha de temer que esos datos se pierdan en su memoria.

Hay diferentes formas de escucha; en la escucha psicoanalítica se rastrea sobre las huellas que deja el paciente libremente dejando de lado una búsqueda en función de las expectativas propias. Para una escucha analítica es necesario aceptar la asociación libre y no contaminarla con directrices y otros taponamientos del discurso. Freud dice: «si nos dejamos llevar por nuestras esperanzas correremos el peligro de no descubrir jamás sino lo que ya sabemos; y si nos guiamos por nuestras tendencias, falsearemos seguramente la posible percepción. No debemos olvi- 
dar que en la mayoría de los análisis oímos del enfermo cosas cuya significación sólo a posteriori descubrimos».

¿Qué elemento se aporta a la escucha para retener tantos datos sin un esfuerzo volitivo consciente? Ya hemos visto que el analista debe escuchar al sujeto sin preocuparse de si retiene o no sus palabras. Podríamos decir que éstas quedan registradas en el inconsciente del analista tintadas de un valor afectivo, de un momento previo y único de encuentro con el paciente.

Sin embargo, compartiendo la opinión de muchos autores contemporáneos, para nosotros la posición en la que se ubica el analista frente al paciente no es neutral en su vertiente contratransferencial. El analista impersonal es una ficción. Para escuchar al paciente en una suerte de encuentro con él hace falta sentir y movilizarse con el material que aporta.

En el mismo texto citado anteriormente, Freud recomienda al analista imponer silencio a todos sus afectos y habla del peligro de una cierta tendencia afectiva. Dice textualmente: «la justificación de esta frialdad de sentimientos que ha de exigirse al médico está en que crea para ambas partes las condiciones más favorables».

Quizás podríamos puntualizar algunos aspectos que, a nuestro juicio, tienen importancia y están en discusión hoy en día. Judy Kantrowitz (5) habla de que aunque la neutralidad y el anonimato del analista son aspectos importantes que salvaguardan el proceso y protegen su buena marcha, el valor de una extremada asepsia se ha de cuestionar.

Freud descubre la contratransferencia pero apenas se ocupa de ella o bien, como puede traslucirse en sus textos, le es incómoda, «un obstáculo que hay que vencer» (también anticipó con su gran capacidad visionaria que su entendimiento estaría ligado al futuro del psicoanálisis). Otros autores contemporáneos trataron la contratransferencia con cierto desdén. Ferenczi (6) en Dominio de la contratransferencia dice que «el psicoanalista debe controlar conscientemente su propia actitud respecto al enfermo y, si es necesario, rectificarla, es decir, dominar la contratransferencia». La frase «dominio de la contratransferencia» en este caso no nos deja indiferentes; nos suena a resistencia, a censura hacia los propios sentimientos del analista.

Frases como las de Freud o Ferenczi hacían de la contratransferencia un objeto incómodo y necesario de expulsar para llevar a cabo el tratamiento. Pero, al hacerlo, también se estaba expulsando una dimensión intersubjetiva que siempre está implícita y que acerca afectivamente a los dos participantes del análisis.

Muy interesante es la observación que hace Etchegoyen (7) para interpretar el factor inconsciente que subyace en el retardo de la valoración de la contratransferencia: «a nadie le resulta grato ver y reconocer su esencial identidad con el paciente que trata abandonando la cómoda, la ilusoria superioridad que ha creído tener».

Creemos que hoy en día la contratransferencia ha de verse como un instru- 
mento necesario para el encuentro con el paciente, un elemento fundamental para la buena escucha y que es ineludible del proceso. La contratransferencia incluye un elemento de resonancia afectiva con el material del paciente.

Por tanto el analista aporta su atención flotante y su contratransferencia al encuentro con el paciente, pero además su propia presencia, pues, quiera o no forma parte del espacio analítico y tendrá un impacto en el paciente.

Es en esta situación conflictiva, en tanto encuentro de dos subjetividades, donde habrá de aparecer la transferencia, base de todo trabajo analítico. Si ésta se está pudiendo elaborar, una determinada vivencia, un determinado contenido, algo de lo que está sucediendo en la transferencia va a posibilitar que se vayan rescatando aquellos fragmentos que quedaban del pasado y encontrar en ellos resignificación.

En la medida en que se pueda conceptualizar así el trabajo analítico, el modo de buscar lo que serían las condiciones técnicas con las que poder llevar adelante este trabajo va a perder importancia si nos atenemos a normas concretas formales de encuadre, y va a ganar importancia si nos atenemos a que este trabajo se esté realizando.

De ahí el problema tan arduo que se estableció desde los comienzos con Ferenczi y con Alexander, cuando crearon las bases de la psicoterapia psicoanalítica. ¿En qué se diferencia un psicoanálisis de este tipo de psicoterapias? Nosotros creemos que lo importante es que el trabajo psicoanalítico se haga, si esto es factible con dos sesiones, con tres o cuatro, con el diván, sin el diván; todo esto pierde importancia, lo importante es que ese trabajo pueda hacerse. Así, a veces, con las condiciones formales perfectamente dadas no hay análisis y con las condiciones formales tomadas con una enorme flexibilidad hay análisis. El análisis y el no análisis no se pueden distinguir por los elementos formales que constituyen el encuadre, sino por el trabajo en transferencia.

Trabajo en transferencia, atención flotante, contratransferencia, son herramientas comunes a la escucha analítica, más allá de la estructura psíquica implicada en el proceso.

La atención flotante es requisito indispensable de una escucha abierta en la que uno se deja llevar por el discurso del paciente. Además, escuchar al paciente implica escuchar la contratransferencia dándole a ésta el lugar de un campo dinámico de encuentro entre dos personalidades que forman una pareja analítica.

Para terminar, una anécdota. Un paciente ingresa en un hospital público por un primer brote de características esquizofrénicas. Se ha dado cuenta de que su abuela y su tía son brujas, capaces de influir en otras personas como su padre, formando un triángulo de poder. Era llamativo el empobrecimiento y la inhibición que presentaba, a pesar del poco tiempo de evolución. Era hijo de una mujer esquizofrénica que se suicidó en medio de una crisis psicótica, viviendo desde enton- 
ces con su padre. Como es habitual se citó a su familia para recoger datos. Aparecieron en la entrevista su padre y su tía, cuya relación era pésima.

Mientras el paciente se mostraba ensimismado, ambos se culparon de la enfermedad del chico, convirtiendo la reunión en una pelea. La tía acusó al padre de ser el culpable de la muerte de su hermana por descuidarla, de la misma forma que había descuidado a su hijo y éste había caído enfermo. El padre insistió en su total disponibilidad para su hijo. Al terminar la entrevista el paciente acudió, de forma espontánea, a hablar con el médico. Le preguntó, mirando de frente: qué, ¿entiendes ya lo que me pasa? El médico contestó que sí.

Si existió una mejoría después de esa conversación o no quizás sea lo de menos, porque para el médico sí cambió la relación con el enfermo.

La escucha psicoanalítica permite la identificación de este médico con la locura de su paciente y la de todos los profesionales que, entre comillas, se vuelven un poco locos con sus pacientes.

Es la herramienta para entender al paciente, aunque las circunstancias no sean propicias y la patología lo ponga difícil, permitiendo un intercambio único entre ambos.

\section{BIBLIOGRAFÍA}

(1) Freud, S., «Nuevos caminos de la terapia psicoanalítica», Obras completas, Tomo XVII, Buenos Aires, Amorrortu, 1918.

(2) UlNiK, J. C., «Revisión critica de la obra de Pierre Marty», Aperturas Psicoanalíticas, Revista de Psicoanálisis, 1999, www.aperturas.org/5Ulnik.htlm

(3) RACKER, H., Estudios sobre técnica psicoanalítica, Buenos Aires, Paidós, 1966.

(4) Freud, S., «Consejos al médico en el tratamiento psicoanalítico», Obras completas, Tomo XII, Buenos Aires, Amorrortu, 1912.

(5) KANTROWITZ, J., «La función del preconsciente en psicoanálisis», Rev. Aperturas psicoanalíticas, Revista de Psicoanálisis, 1999, www.aperturas.org/kantrowitz.htlm

(6) FerenczI, S., «La técnica psicoanalítica», Obras Completas, tomo II, Madrid, EspasaCalpe, 1919. 1993.

(7) Etchegoyen, H., Los fundamentos de la técnica psicoanalítica, Buenos Aires Amorrortu,

(8) FReUd, S., «Construcciones en psicoanálisis», Obras completas, tomo XXIII, Buenos Aires, Amorrortu, 1932.

(9) Grinber, L., El psicoanálisis es cosa de dos, Valencia, Promolibro, 1996.

(10) ZuCKerfeld, R., Acto bulímico, cuerpo y tercera tópica, Buenos Aires, Paidós, 1992.

* Juan Rodado, Psiquiatra-Psicoanalista, Servicio de Psiquiatría. Hospital General Universitario Reina Sofía de Murcia; Elena Sanz, Psiquiatra-Psicoanalista, Centro Psicoanalítico de Madrid; Juan Otero, Psicólogo-Psicoanalista, CSM Dos hermanas. Sevilla.

Correspondencia: Servicio de Psiquiatría. Hospital General Universitario Reina Sofía de Murcia. Avda. Intendentente Jorge Palacios, 1, 30003 Murcia. jvrodado@um.es 